Article

\title{
An Artificial Intelligence-Based Model for Prediction of Parameters Affecting Sustainable Growth of Mobile Banking Apps
}

\author{
Nadire Cavus ${ }^{1,2} \mathbb{D}$, Yakubu Bala Mohammed ${ }^{2,3, *}$ and Mohammed Nasiru Yakubu ${ }^{4}$ \\ 1 Computer Information Systems Research and Technology Centre, Near East University, \\ Nicosia 99138, Cyprus; nadire.cavus@neu.edu.tr \\ 2 Department of Computer Information Systems, Near East University, Mersin 61300, Turkey \\ 3 Department of Computer Science, Abubakar Tatari Ali Polytechnic, 740272 Bauchi, Nigeria \\ 4 American University of Nigeria, 98 Lamido Zubairu Way, 640231 Yola, Nigeria; mnyaku-bu@gmail.com \\ * Correspondence: 20195398@std.neu.edu.tr
}

check for updates

Citation: Cavus, N.; Mohammed, Y.B.; Yakubu, M.N. An Artificial Intelligence-Based Model for Prediction of Parameters Affecting Sustainable Growth of Mobile Banking Apps. Sustainability 2021, 13, 6206. https://doi.org/10.3390/ su13116206

Academic Editor:

Maxim A. Dulebenets

Received: 15 May 2021

Accepted: 28 May 2021

Published: 31 May 2021

Publisher's Note: MDPI stays neutral with regard to jurisdictional claims in published maps and institutional affiliations.

Copyright: (c) 2021 by the authors. Licensee MDPI, Basel, Switzerland. This article is an open access article distributed under the terms and conditions of the Creative Commons Attribution (CC BY) license (https:// creativecommons.org/licenses/by/ $4.0 /)$.

\begin{abstract}
Nowadays, mobile banking apps are becoming an integral part of people lives due to its suppleness and convenience. Despite these benefits, yet its growth in evolving states is beyond expectations. However, using mobiles devices to conduct financial transactions involved a lot of risk. This paper aims to investigate customers' reasons for non-usage of the new conduits in developing countries with distinct interest in Nigeria. The study adopts two methods of analysis, artificial intelligence-based methods (AI), and structural equations modeling (SEM). A feed-forward neural network (FFNN) sensitivity examination technique was used to choose the most dominant parameters of mobile banking data collected from 823 respondents. Four algebraic directories were used to corroborate the study AI-based model. The study AI results found risk, trust, facilitating conditions, and inadequate digital laws to be the most dominant parameters that affect mobile banking growth in Nigeria, and discovered social influence and service quality to have no influence on Nigerians' resolve to use moveable banking apps. Moreover, the results proved the superiority of AI-based models above the classical models. Government and pecuniary institutes can use the study outcomes to ensure secured services offering, and improve growth. Finally, the study suggests some areas for future studies.
\end{abstract}

Keywords: artificial neural network; security and privacy; mobile banking apps; artificial intelligence

\section{Introduction}

Mobile banking is a podium in which clients access their bank reserves while on the move, at any suitable time and area, using any device. It provides location-based dealings and other economic services like expense payments for goods or rendered services, savings, inter-account funds transfer via mobile platforms [1]. The advent of modern smartphones increased efficiency not only in the banking sector, but also in other business organizations [2]. Zhang [3] stressed that there is reasonable upsurge on the quantity of smartphones usage in developed and few developing nations of the world. These days, smartphones help banks to offer different kinds of services to their customers, as majority of the banks if not all are now launching different forms of apps for financial dealings [4]. The utilization of smartphones by individuals to conduct pecuniary activities initiates the thought of what is today termed as mobile banking [5]. Similarly, the number of smartphones users worldwide is above one billion as on 2019. Device suppleness and movability is likely to be the main reasons for the increase, as it affords account flexibility and portability [6]. Furthermore, mobile banking apps reduce customers' operation time and removes geographical barriers [7], as clients can send money to their colleagues, friends, and relatives using just only the device keypad, unlike the traditional dealings that 
requires customers' physical presence [1]. Additionally, mobile devices play an important role in how banking and other commercial activities are being carried out as the device rapidly upsurges transaction speed, suppleness, and abridged the cost of transactions [8]. However, despite these benefits and many more as pointed out in prior studies e.g., see $[9,10]$, its growth in most of the evolving nations is far less than what is seen in advanced nations [11]. Furthermore, little investigations were carried out in Nigeria, in connection to Internet and mobile banking [12,13]. However, Baptista [10] argued that the pace at which $\mathrm{m}$-banking is progressing in Nigeria and other developing countries is disturbing compared to some Asian-Pacific nations and European states. Furthermore, none of the previous m-banking studies conducted in the study area investigates security- and privacy-related parameters that affect the sustainable growth of moveable banking apps. Based on these and the absence of AI-based methods, this paper aims at investigating customers' reasons for rebuffing mobile banking apps in developing nations with special attention in Nigeria, using artificial neural network (ANN), predictions model. The study results will assist banks and other pecuniary institutions in understanding the security and privacy determinants of moveable banking usage, and government authority in formulating digital laws in order to reduce peoples' resistance to usage and improve adoption level for sustainable growth of moveable banking conduits. Related m-banking studies, and approach used in the study are discussed in Section 2, while findings that emerged from the study are summarized in Section 3. Section 4 picks up from Sections 2 and 3 by discussing the parameters that affects mobile banking growth in the study area and other developing nations. Conclusions, and direction for future studies are discussed in Section 5.

\section{Materials and Methods}

\subsection{Mobile Devices, Mobile Banking, and Mobile Banking Apps}

Literature [14], has shown that, the world has continued to witnessed tremendous growth in the area of emerging technologies. Banking industry is one of the sectors that witnessed more domineering innovation advances in the form of "mobile banking apps". Apart from the usual practice of making and receiving calls, modern smartphones have surely altered the traditional channels of messaging between individuals and banks [15]. Scholars have extensively taken this phenomenon and recognized that the prevalent diffusion of moveable phones in the areas of electronic dealings would completely change the methods of doing business, as people can now make purchase anywhere, anytime via mobile phones, which in turn benefits customers, banks, and other financial services providers by offering a universal computing payment solution [16].

Tijani [17], defined Internet and moveable banking as a platform that bridges geographical and time barriers via e-services, as clients can conduct pecuniary transaction even on the move. It is a method in which people make, funds transfer and bill payments electronically through mobile devices. The number of people using moveable devices contributed to the recent deployment of moveable banking apps by banks in both advanced and developing nations, as the number of mobile users now is above 1-billion worldwide [18], some of whom are children, disable, or elderly people all demanding for location-based services. Moreover, device movability and suppleness contributed to the increase in the number of users. Furthermore, cost of smartphone nowadays plays a substantial role with regards to the device usage in conducting banking activities in industrialized nations, as it costs little of employee monthly earning to purchase a smartphone that supports Internet applications [1].

\subsection{Security and Privacy Issues of Mobile Banking Apps}

Despite the increased smartphones users across the globe, utilization of moveable devices for pecuniary purposes was limited to elite and city customers in most African states, from which Nigeria is not exempted [19]. For instance, Nigeria as on September, 2019 has over 121 million GSM subscribers, yet the percentage of those using mobile device for pecuniary dealings is still beyond the banking sector expectation [12]. This may 
not be unconnected to customers' uncertainties about the new services platform as most people do not have faith on the service channels [17]. According to Eshet [20], it is only when clients have confidence on the interface, trust the connections that convey their cash, and organization staff who manage their cash. Moreover, have faith on the banks before they can accept new innovations [7], in a manner that the industry expects [4]. Another factor responsible for slow development of mobile banking is risk or security uncertainty. Most customers are worried about uncompleted transactions, and the difficulties involved in tracing or retrieving uncompleted transactions, as it usually takes weeks or months in developing nations for banks to rectify the problems [9], thus, affecting acceptance of the new platform. Furthermore, payments through moveable devices were open to attacks, unlike the traditional payment methods, as third-party intrusion still takes place in mobile devices via other apps stored in the device, such as emails, word processing, and other social networking apps [21]. Furthermore, cost of mobile devices that support mobile banking apps and Internet subscriptions cost are other inhibiting factors that affect mobile banking development in most African countries. At present, the cost of mobile device that enable Internet usage may take a little percent of the customer's monthly earning in advanced nations like France, UK, Germany, the USA, and other parts of the world [1], but majority of salary earners in African countries and other developing countries, may probably require double of their monthly earning to buy these compactible phones, thus affecting mobile banking usage [22] in these nations.

\subsection{Artificial Intelligence (AI) Based Techniques}

Literature, e.g., see [23-25], has shown that factors affecting mobile banking growth in both developing and developed nations are examined using classic models such as partial least square, least square, and Pearson correlation. However, Nourani [26] argued that prediction results based on these methods are biased in nature, and sometimes produced unreliable and inaccurate results compared to AI-based methods such as ANN, CNN, BRT, SVM, and ANFIS. According to Cavus [27], AI-based methods are more robust, accurate, and flexible than the classic methods, especially for research that are complex in nature e.g., emotions, attitudes, and behaviors. For this and other reasons, an AI-based method (ANN) was used in this study to obtain accurate and reliable results (predictions) with regards to the effects of security and privacy parameters on mobile banking growth in Nigeria.

\subsection{Method}

\subsubsection{Research Models}

According to Malaquias [1], the real acceptance of new innovations at initial instance requires acceptance from probable users, and diverse research works have been developed to expand the judgement of issues that contributed to peoples' resistance to accept modern technologies. DeLone and McLean [28] revised "model of Information Systems success" that has been extensively used by scholars to ascertain "users' acceptance" of different information systems. The original model mentioned six issues that are likely to affect the system's triumph, i.e., "system quality, information quality, system use, user satisfaction, individuals and organizational impacts." However, Tam [29], in their work stressed the importance of services excellence, thus included "service quality" to the already existing "six variables of D\&M model" in order to have more insight on customers' reasons for accepting or rejecting a particular technological change that arise.

Another model used for measuring customers' action on new innovations is the revised "unified theory of acceptance and usage of technology" (UTAUT), by Venkatesh [30]. In this study, we combined the two models together i.e., "D\&M model and UTAUT model" to further investigate the level of mobile banking apps usage and identify the factors that led to customers snub of mobile banking apps in Nigeria. However, after a thorough deliberation and comments from current literatures on "mobile banking apps" challenges in developing nations, especially Nigeria, the study integrates three additional variables of "Trust and Risk" as per Munoz-Leiva [31], and Legal framework into the study classic 
model. Trust/faith and risk were the two main factors affecting customers' intent to use mobile banking apps in a large number of developing nations [32]. Similarly, Weber [33] in their study stressed the importance of "Legal Framework" or in other words, laws that regulate digital realm activities, as absence of laws that specifically regulate Internet activities persist in most developing countries. The classic model consists of eight independent variables (Service quality, Information quality, System quality, Trust, Legal Framework, Risk, Facilitating Condition, Social Influence), and two mediating variables of (Satisfaction and Intention to Use) as shown in Figure 1.

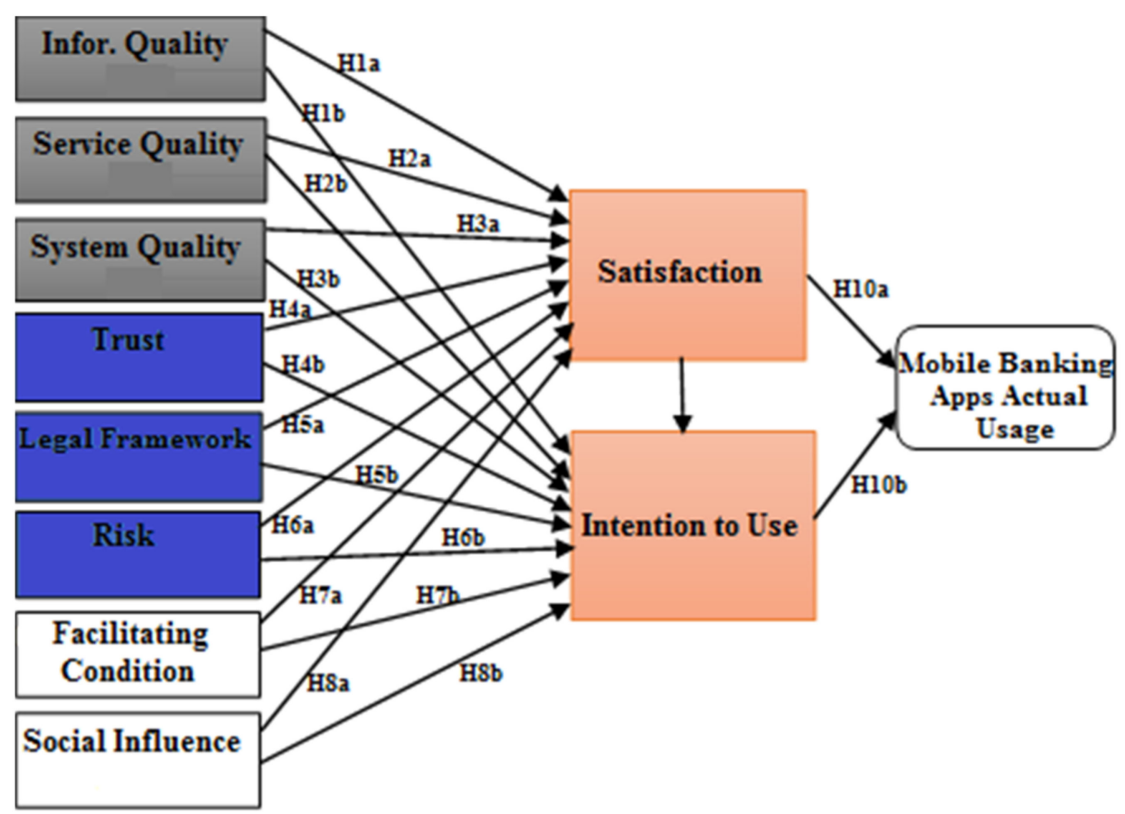

Figure 1. Study classic model (Hb-Hypothesis formulation in Section 2.5).

Actual usage in the classic model represents the dependent variable of mobile banking apps; while the first three independent variables of "Information quality, Service quality and System quality", together with the two mediating variables of "Intention to use" and "User satisfaction," and dependent variable of actual usage were sourced from the updated D\&M models of Tam [29]. While the second three independent variables of "trust and risk" were explored from prior studies [16,34], and Legal framework was formulated as suggested by Weber [33]. Finally, the last two independent variables "Facilitating conditions and Social influence" were obtained from [30,35] (see Appendix A).

\subsubsection{Reliability Analysis of the Study Classic Model}

The quality of all the constructs was calculated using Cronbach Alpha (CA), so that consistency levels among the study objects can be ascertained. Table 1 , shows that the CA values for all constructs of the proposed model stood above 0.70. According to Calisir [36], constructs' uniformity level is considered to be good if the CA values are equal or greater than 0.70 . Therefore, it can be said that there is a sensible uniformity among the proposed research model constructs. Furthermore, as shown in Table 1, composite reliability (CR) was also calculated to further confirm the uniformity values produced by Cronbach alpha, and the results were also greater than 0.70 , reaffirming the consistency level among the constructs. The reliability examination results showed that the quality of all the constructs in the proposed model is acceptable. 
Table 1. Reliability examination results.

\begin{tabular}{|c|c|c|c|c|}
\hline Construct & Items & Load. (std.) & CA & CR \\
\hline \multirow{3}{*}{ Information Quality (IQ) } & IQ1 & 0.902 & \multirow{3}{*}{0.853} & \multirow{3}{*}{0.872} \\
\hline & IQ2 & 0.892 & & \\
\hline & IQ3 & 0.913 & & \\
\hline \multirow{3}{*}{ Service Quality (SQ) } & SQ1 & 0.844 & \multirow{3}{*}{0.786} & \multirow{3}{*}{0.797} \\
\hline & SQ2 & 0.894 & & \\
\hline & SQ3 & 0.950 & & \\
\hline \multirow{3}{*}{ System Quality (SYSQ) } & SYSQ1 & 0.861 & \multirow{3}{*}{0.847} & \multirow{3}{*}{0.873} \\
\hline & SYSQ2 & 0.851 & & \\
\hline & SYSQ3 & 0.958 & & \\
\hline \multirow{3}{*}{ Trust (TR) } & TR1 & 0.713 & \multirow{3}{*}{0.850} & \multirow{3}{*}{0.887} \\
\hline & TR2 & 0.630 & & \\
\hline & TR3 & 0.640 & & \\
\hline \multirow{3}{*}{ Legal Framework (LF) } & LF1 & 0.892 & \multirow{3}{*}{0.802} & \multirow{3}{*}{0.843} \\
\hline & LF2 & 0.787 & & \\
\hline & LF3 & 0.701 & & \\
\hline \multirow{3}{*}{ Risk (R) } & R1 & 0.935 & \multirow{3}{*}{0.893} & \multirow{3}{*}{0.913} \\
\hline & $\mathrm{R} 2$ & 0.878 & & \\
\hline & R3 & 0.920 & & \\
\hline \multirow{3}{*}{ Facilitating Conditions (FC) } & FC1 & 0.978 & \multirow{3}{*}{0.819} & \multirow{3}{*}{0.830} \\
\hline & FC2 & 0.907 & & \\
\hline & FC3 & 0.932 & & \\
\hline \multirow{3}{*}{ Social Influence (SI) } & SI1 & 0.967 & 0.773 & 0.789 \\
\hline & SI2 & 0.982 & \multirow[t]{2}{*}{0.853} & \multirow[t]{2}{*}{0.872} \\
\hline & SI3 & 0.868 & & \\
\hline
\end{tabular}

CA: Cronbach's Alpha; CR: composite reliability.

\subsubsection{Artificial Neural Network (ANN) Model of the Study}

The study data were normalized as per Zhou [37], before importing to the network in order to avoid variables with higher response scale overwhelming the others. Figure 2 depicts the structure of the study ANN model.

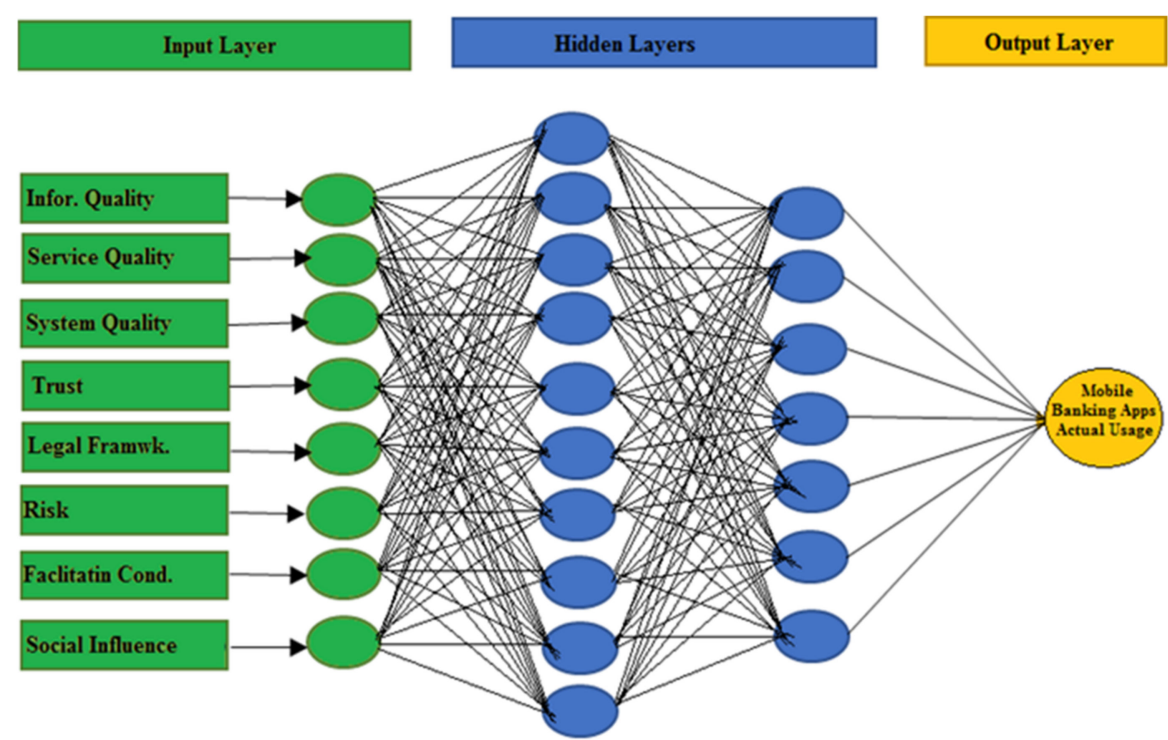

Figure 2. Study artificial neural network model.

As showed in Figure 2, the input layer comprises the eight independent variables of the study and the output layer contains the study target, i.e., m-banking usage, while the 
hidden layer consists of only two hidden neurons, as number of neurons has no influence on the network prediction [38]. The network synaptic weights were declared as per Van Gerven [39].

\subsection{Hypotheses Formulation}

\subsubsection{Information Quality}

Nowadays, excellent provision of information from banks to customers plays an important role in customers' resolve to use mobile banking apps [16]. Customers need not only quality information, but also an up-to-date information [7]. Information quality includes but is not limited to provision of complete information, updated information, but also in a language that customers can read and understand [29]. Moreover, customers feel happy and satisfied whenever they receive relevant and updated information about a new technology in a timely manner, thus influencing their behaviors toward accepting a new technology. Therefore, information quality brings about satisfaction, and satisfaction influences the intention to positive usage [40].

Hypothesis 1a (H1a). The quality of information provided has positive association with the intention to use and sustainable growth of mobile banking apps in Nigeria.

Hypothesis $\mathbf{1 b}(\mathbf{H} 1 \mathbf{b})$. Influence of information quality on customers' intention is moderated by satisfaction.

\subsubsection{Service Quality}

Service excellence is considered as one of the key determinants of mobile banking usage. The ways and manners in which banks respond to their customers when they need support or experienced a problem [25], play a substantial role in customers' intent to use mobile banking services [18]. This factor clearly shows that, the higher the quality of services provided by banks and other pecuniary institutes to clients, the higher the customer satisfaction [29]. Therefore, service excellence is very vital to the development of moveable banking in developing nations [41]. Furthermore, [42] observed that the issue of assured service excellence is not only limited to banks alone as mobile banking setting consists of three dimensions [9,34], i.e., pecuniary institutions, telecommunication, and Internet services providers, that served as gateways through which customers perform their financial transactions using mobile devices, and also have a role to play in ensuring excellence service is achieved.

Hypothesis 2a (H2a). The quality of service provided has positive association with the intention to use and sustainable growth of mobile banking apps in Nigeria.

Hypothesis $\mathbf{2 b} \mathbf{b} \mathbf{H} \mathbf{2 b})$. Influence of service quality on customers' intention is moderated by satisfaction.

\subsubsection{System Quality}

Mobile banking services were offered to customers via platforms directly controlled by the banks, as customers only interact with the system through mobile apps on their devices provided by banks. Therefore, system quality turns out to be the operational connector that leads customers' device to system usage $[25,29,43]$. Similarly, in mobile banking setting, system quality should mirror ease of use, immediate feedbacks, effective user interface and reliability $[28,44]$. Absence of these structures, will increase device operational difficulty for users and affect the intention to use the service channels negatively.

Hypothesis 3a (H3a). The quality of m-banking systems has positive relationship with the intention to use and sustainable growth of mobile banking apps in Nigeria.

Hypothesis $3 \mathbf{b}(\mathbf{H} 3 \mathbf{b})$. Influence of systems quality on customers' intention is moderated by satisfaction. 


\subsubsection{Trust}

In the context of mobile banking, trust is the strongest factor of mobile banking usage, and if not carefully managed by banks it may impact negatively on clients' intent to accept electronic platforms [45]. It is only when individuals have faith on the software, Internet connectivity that conveys their funds, banks agents that manage their confidential information, and on the institutions itself before they can accept mobile banking [46] in a manner that the banking industry expects. According to Malaquias [1] and Luo [34], there is a need for mobile banking services providers to do more on the areas of security and privacy issues, because worries for safety and confidentiality were usually more complex on financial dealings via mobile devices. As people store their confidential information such as pin, password, and user-name on these moveable devices. Moreover, people are more concerned about this information falling into other hands due to device lost or theft, thus negatively affecting the intention to use "mobile banking channels" [47]. The integration of trust into the study research model, makes the study more relevant considering the cultural background of Nigerian banking customers, as well as both D\&M and UTAUT models not mentioning trust in their variables.

Hypothesis $4 \mathbf{a}(\mathbf{H 4 a )}$. Trust factor has positive association with the intention to use and sustainable growth of mobile banking apps in Nigeria.

Hypothesis $4 \mathbf{b} \mathbf{( H 4 b )}$. The influence of Trust on customers' intention is moderated by satisfaction.

\subsubsection{Legal Framework}

Legal framework as for this study, is to investigate the influence of legislation, or in other words digital realm laws on Nigerians' resolve to use mobile banking apps. It was argued that the absence of explicit laws that control the Internet environment may negatively affect "mobile banking apps" usage [48]. Internet environment is increasingly becoming more vulnerable than before [32], with the number of crimes committed over the Internet is on the rise nowadays (Internet fraud). People concerns on how to recover their money in an event of financial loses either due to negligence on the part of the bank representatives in handling sensitive information or fraudulent act over the Internet [34], as to what the laws say and how it will be applied in cases of this kind. Inadequate laws on the part of Internet dealings may negatively affect customers' intention to use the platforms. This factor was added to the study model considering the lingering legal issues in Africa, and as well both UTAUT and D\&M models do not state it.

Hypothesis 5a (H5a). Laws that regulate m-baking activities have positive relationship with the intention to use and sustainable growth of mobile banking apps in Nigeria.

Hypothesis $\mathbf{5 b} \mathbf{b} \mathbf{H} 5 \mathbf{b})$. The influence of digital real laws on customers' intention is moderated by satisfaction.

\subsubsection{Risk}

Risk is one of the strongest reasons for non-adapters' rejection of Internet and moveable banking globally, as well as partial use among adopters. It has impacted negatively on the customers' behaviors in most developing nations [43]. Similarly, there is strong correlation between risk and people's lack of interest in mobile and Internet banking dealings [23]. Furthermore, people's understanding of risk significantly affects their trust, thus affecting mobile banking apps usage negatively. Pecuniary institutes need to put adequate security majors for Internet dealings in order to guarantee the safety of clients' cash and other important information, as well as confirming the reliability of mobile banking platforms to their customers [24,34]. Most of the elderly customers fear that screen dimension and keypads of mobile devices might cause them to make mistakes while paying bills 
via mobile banking apps $[8,17]$, because they found it difficult to check and confirm the supplied information [34].

Hypothesis 6a (H6a). Risk associated with m-banking has positive relationship with the intention to use and sustainable growth of mobile banking apps in Nigeria.

Hypothesis $\mathbf{6 b} \mathbf{b} \mathbf{H 6 b})$. The influence of risk on customers' intention is moderated by satisfaction.

\subsubsection{Facilitating Conditions}

Resource facilitating conditions play a significant role in people's determination to accept or reject new technology. People can accept mobile banking apps only if the required resources were available to them [7]. This study attempts to find the impact of resources (e.g., telecommunication services, Internet penetration and speed, and smartphones), that facilitate mobile banking usage in Nigeria, considering the infrastructural deficits in African region [8], in order to see whether it has negative effects.

Hypothesis $7 \mathbf{a}(\mathbf{H 7 a})$. Facilitating conditions have positive relationship with the intention to use and sustainable growth of mobile banking apps in Nigeria.

Hypothesis $\mathbf{7 b} \mathbf{b} \mathbf{H 7 b})$. The influence of resource-facilitating conditions on customers' intention is moderated by satisfaction.

\subsubsection{Social Influence}

People consider some individuals to be very important to them, and their thoughts about the need to embrace a new system impact positively on them [30]. Nigeria is a country with over 371 cultural collections and tribes, each with their own values and traditions and speak dissimilar languages $[49,50]$. Therefore, opinions of certain individuals e.g., cultural and religious leaders play a significant role in the people's intention to embrace new technology in the country, particularly among the rural populace. Majority of the studies conducted in the field of "mobile banking usage" include social influence in their framework [1].

Hypothesis 8a (H8a). Social influence has positive relationship with the intention to use and sustainable growth of mobile banking apps in Nigeria.

Hypothesis $\mathbf{8 b} \mathbf{b} \mathbf{H 8 b})$. The influence of associate on customers' intention is moderated by satisfaction.

\subsubsection{Satisfaction and Intention to Use}

Satisfaction as for this study, is to examine the level of customers' satisfaction with mobile banking stations and determine its influence on customers' intent to use or continual usage. Satisfaction is the main predictor of intention to use or to the continual usage of mobile banking apps in developing nations [51]. Similarly, Munoz-Leiva [31] stressed that customers may not hesitate to abandon moveable banking conduits if it does not satisfy them, but are eager to use when satisfied with the services.

Hypothesis 9 (H9). The relationship between satisfaction, intention to usage, and sustainable growth of mobile banking apps is positive in Nigeria.

\subsection{Participants}

Detail analysis of the respondents' demographic distributions is presented in Table 2; participants' sample characteristics such as gender, age group, educational level, and engagement status were examined. The sample characteristics results produced $59.3 \%$ male and $40.7 \%$ female. The difference between the two gender groups was inconsequential. Age class that formed majority of the survey data was the younger people between 
the age group of 18 and 25 years, $45.4 \%$, followed by 26 and 35 years which account for $35.6 \%$ respectively, while respondents between the age of 36 and above have the lowest representation of $9 \%$. This clearly shows that younger people (Generation Y), are more likely to embrace new technologies as they are used to social media than elderly people (Generation X) [22].

Table 2. Sample demographic distribution.

\begin{tabular}{|c|c|c|}
\hline Demographic Variable & Frequencies & Percentage \\
\hline \multicolumn{3}{|l|}{ Gender } \\
\hline Male & 454 & 59.3 \\
\hline Female & 311 & 40.7 \\
\hline \multicolumn{3}{|l|}{ Age group } \\
\hline $18-25$ & 347 & 45.4 \\
\hline $26-35$ & 272 & 35.6 \\
\hline 36 and above & 146 & 19 \\
\hline \multicolumn{3}{|l|}{ Educational Level } \\
\hline SSCE & 70 & 9.2 \\
\hline ND & 190 & 24.8 \\
\hline Bachelor/HND & 398 & 52 \\
\hline Masters and above & 107 & 14 \\
\hline \multicolumn{3}{|l|}{ Employment status } \\
\hline Academics & 72 & 9.4 \\
\hline Other civil servants & 284 & 37.1 \\
\hline Students & 265 & 34.7 \\
\hline Business peoples & 144 & 18.8 \\
\hline
\end{tabular}

SSCE: senior secondary certificate examination, ND: national diploma, HND: higher national diploma.

\subsection{Data Gathering Procedure}

The survey data were gathered using questionnaire method as suggested by [52]. The technique offers high level of accuracy, flexibility, and allows participants to freely express their feelings without interference from the investigators; thus, it is more suitable for experiment that involves assumptions [43]. The online-survey (google form) links were sent to participants via social networking sites (WhatsApp groups, Facebook). For credibility, a random sampling method was used. However, participation is voluntary i.e., the participants have the right not to partake in the survey if they so wish. Out of the links with feedback forms (823) sent to various customers (consisting of academics, other civil servants, students, and business individuals), 765 forms were determined to be valid. An excellent return rate [53] of 92.9 percent was achieved for the study sample. The survey form has two sections: (A) respondents' educational level, employment status, age, and gender, while the (B) part contains the survey constructs adopted from [16,30,35], comprising eleven constructs (see Appendix A). Likert-scale (5-point), extending from 1-5 (Strongly disagree to Strongly agree), was used to evaluate the measures of our questionnaire items.

\subsection{Data Analysis Methods}

The study data were processed and scrutinized using SPSS and MATLAB. The analysis begins with the participants' demographic distribution. Then, two methods of data analysis, artificial neural network (ANN) and structural equations modelling (SEM) were employed to measure the theoretical model and test the study proposed hypotheses. The use of structural equation modelling (SEM) for testing study hypothesis has been increasing in science-based and social sciences research [9]. The approach offers great benefits for theories advancement and hypotheses testing [54]. For SEM, the study adopted a two-stage technique of analysis used by prior studies $[53,54]$. In the first stage, sample demographic distributions were analyzed using descriptive statistics, while in the second stage, the researchers assessed the questionnaire constructs using two directories of composite reliability (CR) and Cronbach's alpha (CA), where 0.80 is considered good, 
0.70 accepted, 0.60 questionable and 0.50 poor [55]. ANN comprises of three pieces of layers; an input layer with input or independent variables connected to one or more hidden layers, which provides information to output layer. For ANN to execute tasks, network input weights require adjustments in order to reduce the error between anticipated output and real outputs [56]. ANN are undergoing a renaissance that do not only alters artificial intelligence (AI) field, but also provides new visions about neural computational opportunity for researchers in computer-related fields [39]. Furthermore, researchers in social sciences now use ANN to validate and measure the performance of study models [57]. These contributions defined the efficacy of neural networks in both science and social sciences experiments. This study used ANN to measure and validate the study research model by comparing target output with the predicted values obtained from the neural network.

\subsection{Sensitivity Analysis}

According to Nouran [26], the effectiveness of any AI model depends on the number of dependent variables used in the model. The authors argued that using too much dependent variables will upsurge the model complexity and lead to model overfitting. While using fewer input variables on the other hand can affect the prediction ability of the model. As seen in Figure 2, neither few nor too much input parameters were used in this study to avoid model overfitting, and obtained accurate results with regards to the factors affecting moveable banking growth in Nigeria. For sensitivity investigation, a feed-forward neural network (FFNN) sensitivity examination technique was used instead of the normal classic methods due to it robustness. Moreover, Reim [58] argued that AI-based techniques such as ANN, ANFIS, CNN, and SVR have the ability to handle data uncertainty, thus producing more accurate and reliable results than the classical methods. Coefficient of determination (DC) method was used to evaluate and rank the effects of each of the input parameters on mobile banking apps usage in the study area. The closer the parameter values to 1 , the more effect it has on mobile banking apps actual usage and vice versa. Figure 3 depicts the structure of the study methodology.

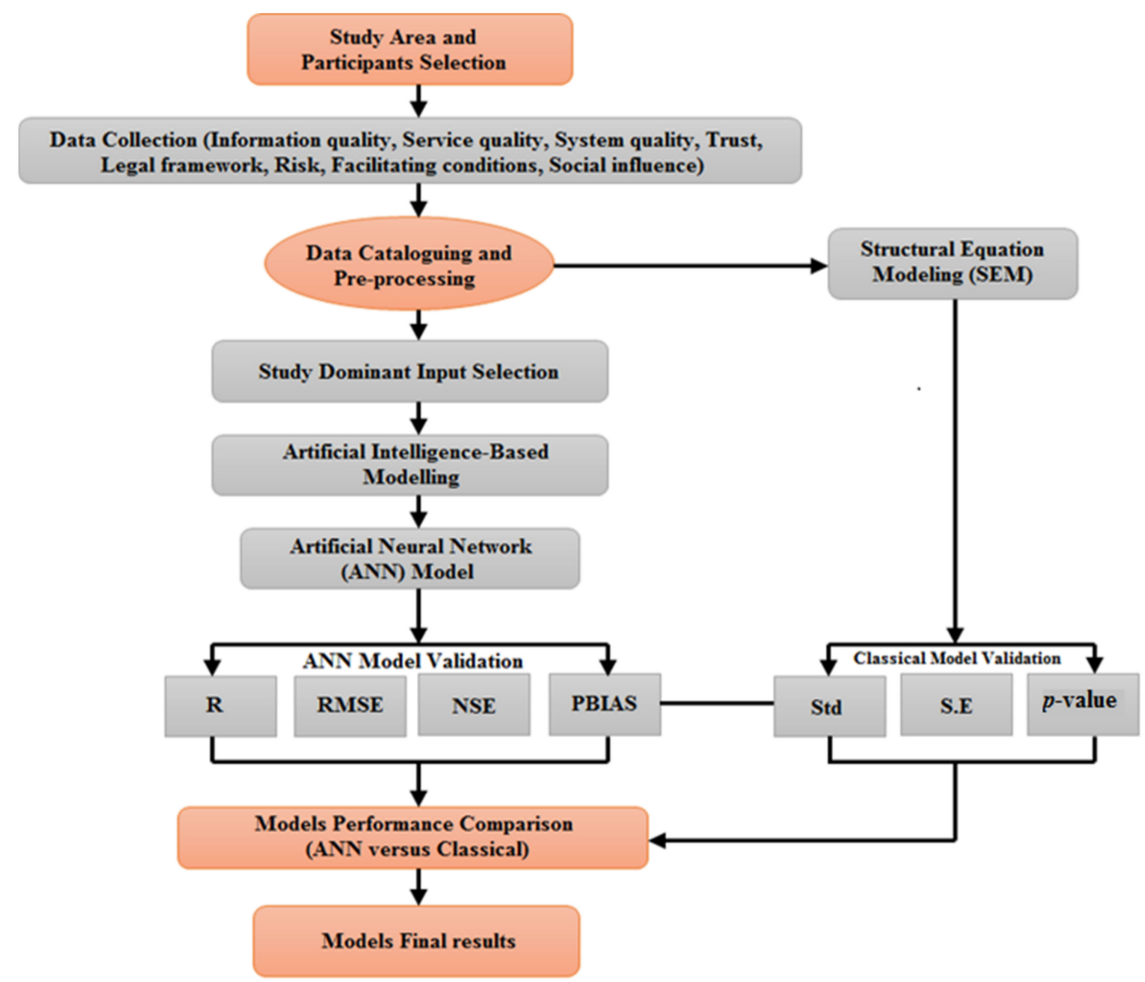

Figure 3. Structure of the study methodology. 
As shown in Figure 3, the study methodology comprises four major steps. Area and participants for the study were selected in the first step, while data for the study were collected, pre-processed, and the study models were built and validated in the second stage. Performance of the study models (i.e., ANN model and Classic model) was compared in the third stage, while final outcomes of the models were obtained in the fourth stage.

\section{Results}

Results concerning the effects of each of the input parameters on moveable banking apps development, training, and testing scatter plots for computed and observed data, sensitivity examination result, and prediction results of the study models are offered in the following subsections.

\subsection{Pre-Processing and Performance Assessment of the Study Input Parameters}

Data obtained from the study input variables were pre-processed first, followed by the performance assessment of each of the input parameters using average DC in order to determine the sensitivity of each parameter used in the study.

Sensitivity Examination Results

The results of moveable banking security and privacy forecasters based on parameters sensitivity evaluation is offered in Table 3, using Equation (1).

$$
D C=1-\frac{\sum_{i=1}^{n}\left(N_{o b s i}-N p r e i\right) 2}{\sum_{i=1}^{n}\left(N_{o b s i}-N_{o b s i}\right) 2}
$$

$n$ represents the sum of the observations made, while Nobsi represents the observed effects of security and privacy parameters on mobile banking apps usage, while Nprei represents the predicted effects security and privacy on moveable banking apps. Table 3 , highlights the sensitivity examination results for the study input parameters.

Table 3. Sensitivity examination results.

\begin{tabular}{ccc}
\hline Input Parameters & Average DC Values & Rank \\
\hline Risk & 0.9710 & 1 \\
\hline Trust & 0.9501 & 2 \\
\hline Facilitating conditions & 0.9492 & 3 \\
\hline Legal framework & 0.8920 & 4 \\
\hline System quality & 0.8831 & 5 \\
\hline Information quality & 0.8112 & 6 \\
\hline Social influence & 0.6820 & 7 \\
\hline Service quality & 0.6533 & 8 \\
\hline
\end{tabular}

As seen in Table 3, the most dominant security and privacy parameters that affect mobile banking development in the study area are: Risk, Trust, and Facilitating conditions as their average DC values stood above 0.9, while digital laws (Legal framework), System and Information qualities constitute the second most dominant inputs. Moreover, the sensitivity examination results indicated that Service quality and Social influence have less effects on moveable banking development in the study area.

\subsection{Results of Structural Equation Modeling (SEM)}

The study-proposed hypotheses were first tested using SEM. As shown in Figure 4, the testing outcomes for all the variables in the study-proposed SEM model clearly show that all the proposed hypotheses were supported. 


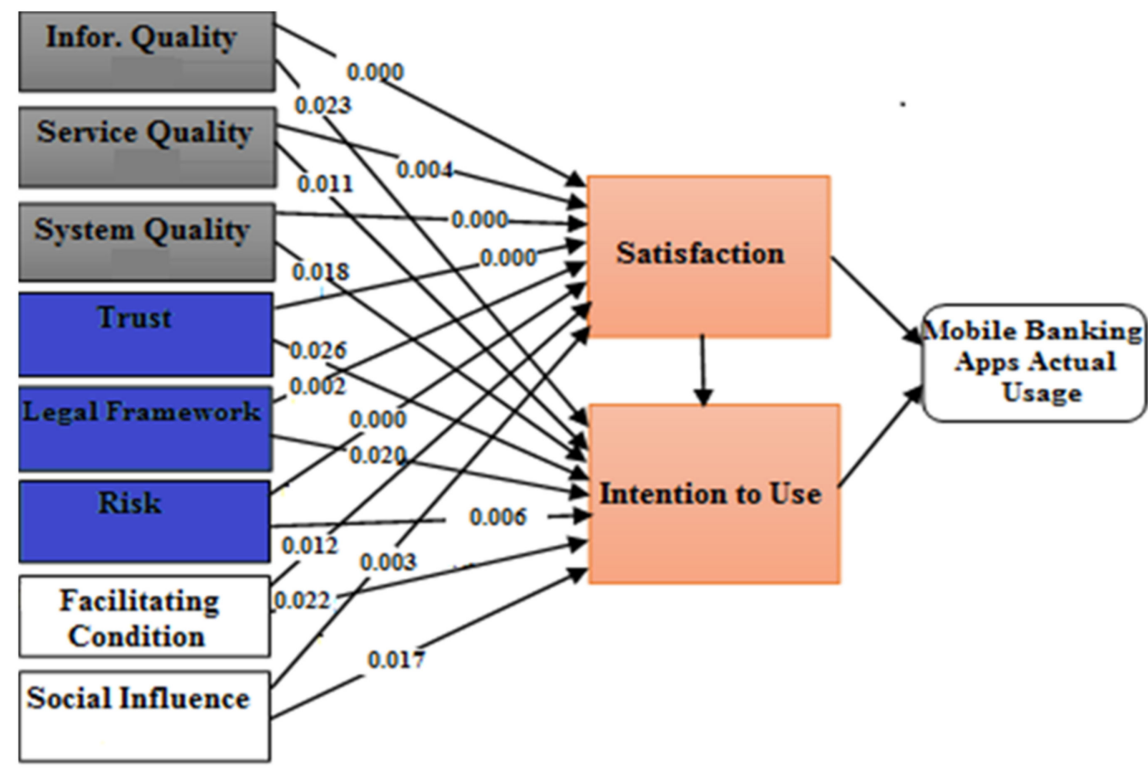

Figure 4. SEM results for the proposed research model.

Trust $p$-values of 0.000 and 0.026 , as showed in Figure 4 , indicated that Nigerians' interpretation of trust has a direct association with mobile banking apps development as reasonable number of customers demonstrate lack of confidence either on the banks or m-banking transactions channels, thus affecting the intention to use it. This result strengthens the thoughts that trust intuition affects m-banking usage in most developing nations [42,45]. As shown in Figure 4, "Legal framework" p-values of 0.002 and 0.020, "Legal framework" $p$-values of 0.002 and 0.020 , clearly show that absence of clear Internet legislation or in other words, digital laws impacted negatively on customers intentions to use mobile banking apps in Nigeria which in turns affect its progress. Furthermore, "risk" SEM results of 0.000 and 0.006 signifies the importance of risk factor in e-transactions channels, the result showed that customers' fear of third parties accessing or their account information being visible is the major reason why most of the customers in Nigeria do not adopt mobile banking. Risk is one of the most significant factors that affect mobile banking development globally. Similarly, as seen in Figure 4, the results of "Information Quality" 0.000 and 0.023, "Service Quality" 0.004 and 0.011, "Systems Quality" 0.000 and 0.018 , and "Facilitating Conditions" 0.012 and 0.022 showed that infrastructural deficit is another factor that has negative effect on mobile banking apps usage in Nigeria. The results reflect that, reasonable number of Nigerians turn down mobile banking apps due to either high cost of Internet subscriptions, smartphones that support mobile banking apps, poor Internet or telecommunication services, thus affecting the adoption level in the country. The results showed similar sign as per Gupta [43]. Moreover, $p$-values of 0.003 and 0.017 showed that "societal influence" has direct association with individuals" commitment to use mobile banking apps in Nigeria. This may not be unrelated with the country's diverse cultural background. Although the proposed research model results based on the SEM testing show that all the study-proposed hypotheses were positive as shown in Table 4, it indicates that all the hypotheses were supported in Nigeria. However, the main focus of this study is to use ANN prediction model in order to determine the effects of security and privacy issues on the intent to use and continue using moveable banking apps in Nigeria, and further prove the superiority of ANN prediction model above the classical models used by large number of researchers. The study SEM testing results is presented in Table 4. 
Table 4. SEM testing results.

\begin{tabular}{lccccc}
\hline Hypotheses & Parameters & Std. & S.E. & $p$-Value & Results \\
\hline $\mathrm{H} 1 \mathrm{a}$ & Information quality $\rightarrow$ Intention to use & 1.124 & 0.041 & 0.000 & Supported \\
$\mathrm{H} 1 \mathrm{~b}$ & Information quality $\rightarrow$ Satisfaction & 1.128 & 0.044 & 0.023 & Supported \\
\hline $\mathrm{H} 2 \mathrm{a}$ & Service quality $\rightarrow$ Intention to use & 0.855 & 0.030 & 0.004 & Supported \\
$\mathrm{H} 2 \mathrm{~b}$ & Service quality $\rightarrow$ Satisfaction & 0.895 & 0.038 & 0.011 & Supported \\
\hline $\mathrm{H} 3 \mathrm{a}$ & System quality $\rightarrow$ Intention to use & 0.871 & 0.032 & 0.000 & Supported \\
$\mathrm{H} 3 \mathrm{~b}$ & System quality $\rightarrow$ Satisfaction & 0.912 & 0.063 & 0.018 & Supported \\
\hline $\mathrm{H} 4 \mathrm{a}$ & Trust $\rightarrow$ Intention to use & 0.644 & 0.023 & 0.000 & Supported \\
$\mathrm{H} 4 \mathrm{~b}$ & Trust $\rightarrow$ Satisfaction & 0.651 & 0.037 & 0.026 & Supported \\
\hline $\mathrm{H} 5 \mathrm{a}$ & Legal framework $\rightarrow$ Intention to use & 0.862 & 0.029 & 0.002 & Supported \\
$\mathrm{H} 5 \mathrm{~b}$ & Legal framework $\rightarrow$ Satisfaction & 0.712 & 0.018 & 0.020 & Supported \\
\hline $\mathrm{H} 6 \mathrm{a}$ & Risk $\rightarrow$ Intention to use & 0.921 & 0.033 & 0.000 & Supported \\
$\mathrm{H} 6 \mathrm{~b}$ & Risk $\rightarrow$ Satisfaction & 0.873 & 0.038 & 0.006 & Supported \\
\hline $\mathrm{H} 7 \mathrm{a}$ & Facilitating condition $\rightarrow$ Intention to Use & 0.936 & 0.034 & 0.012 & Supported \\
$\mathrm{H} 7 \mathrm{~b}$ & Facilitating condition $\rightarrow$ Satisfaction & 0.883 & 0.047 & 0.022 & Supported \\
\hline $\mathrm{H} 8 \mathrm{a}$ & Social influence $\rightarrow$ Intention to use & 0.926 & 0.033 & 0.003 & Supported \\
$\mathrm{H} 8 \mathrm{~b}$ & Social influence $\rightarrow$ Satisfaction & 0.712 & 0.016 & 0.017 & Supported \\
\hline
\end{tabular}

Note: 0.05 level of significance is the accepted level for all the study hypotheses.

The $p$-values for all the study hypotheses were less than 0.05 , indicating that all the hypotheses were significant, as shown in Table 4.

\subsection{Results of Artificial Neural Network (ANN) Modeling}

AI-based method (ANN) was used to test the study parameters. It was first trained with all the survey parameters as network input to get an overall prediction for the proposed ANN model, and later trained with the constructs of each parameters separately in order to determine protection and privacy issues involved in Internet and other moveable banking, and to find out the factors responsible for Nigerians' rebuff of mobile banking apps usage.

As shown in Figure 2, the study ANN model has three layers. Input layer with eight input parameters which were normalized, using Equation (2).

$$
x n=\frac{x-x \min }{x \max -x \min }
$$

where, $x=$ input, $n=$ numbers of variable, and $\frac{x \min }{x \max }=\left(\begin{array}{ccc}x & x_{1} & x_{n} \\ x \min & 0, & 0, \\ x \max & 1, & 1,\end{array}\right)$. Therefore, $x$ ranges between [ 0 and 1 ]. The hidden layers synaptic weights range between [ 0.1 and 1.0$]$ and the output layer represents mobile banking apps' actual usage (target) to be $\gamma=1$. The study data were normalized and imported into our artificial neural network and the network was trained. TANSIG and MSE were chosen as transfer and performance functions, while TRAINLM as training function and Feed-forward backprop as the network type in training for both the overall and sole ANN models. Figure 5, displays the overall model concert. 


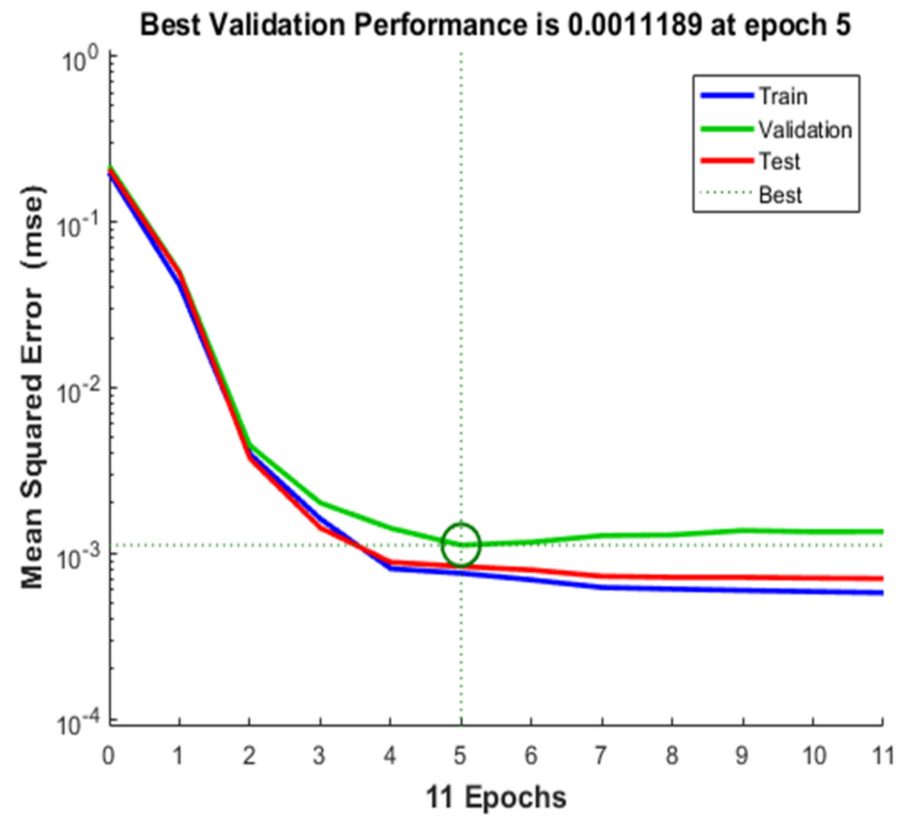

Figure 5. Iteration result of the study ANN model.

As seen in Figure 5, the mean squared error (MSE) of the overall ANN model turns to be pretty good, as the optimum validation performance was achieved at epoch 5 with the MSE value (0.001) out of 11 epochs, signifying the correctness of the network input variables such as "Risk", "Trust", "Information and Systems qualities", "Legal Framework", and "Facilitating conditions" in predicting factors that affect mobile banking apps usage in Nigeria. Furthermore, the MSE value (0.001) clearly shows that the study data fitted well on the curve data points line. Performance results of the study ANN model are presented in Table 5. Five statistical indices were used to measure the performance of the study ANN model namely; correlation coefficient (R), root mean square error (RMSE), Nash-Sutcliffe efficiency (NSE), and percentage bias (PBIAS). As seen in Table 5, the model has $R$ values of 1.0000 and 0.9998 in training and testing. The closer the value of $R$ to 1 , the significant the relationship between the dependent and independent variables. While $R$ is a relative measure of model fit, RMSE on the other hand measured how accurate the model prediction values are to the observed data. Low RMSE values indicate an accurate prediction. In this case, an RMSE values of 0.0012 and 0.0013 clearly shows that the model has an accurate prediction. Furthermore, the ANN model NSE values of 0.9998 for both training and testing, signify how good the simulated and observed data fits the plot lines. Similarly, the PBIAS values of 0.0011 and 0.0012 shows that the model-simulated values are neither larger nor smaller than the observed values. Scatter plots for the study AI-based model is presented in Figure 6.

Table 5. ANN modelling results.

\begin{tabular}{ccccccccc}
\hline & Training & \multicolumn{9}{c}{ Testing } \\
\hline MODEL & $\mathbf{R}$ & RMSE & NSE & PBIAS & $\mathbf{R}$ & RMSE & NSE & PBIAS \\
\hline ANN & 1.0000 & 0.0012 & 0.9998 & 0.0011 & 0.9998 & 0.0013 & 0.9998 & 0.0012 \\
\hline
\end{tabular}



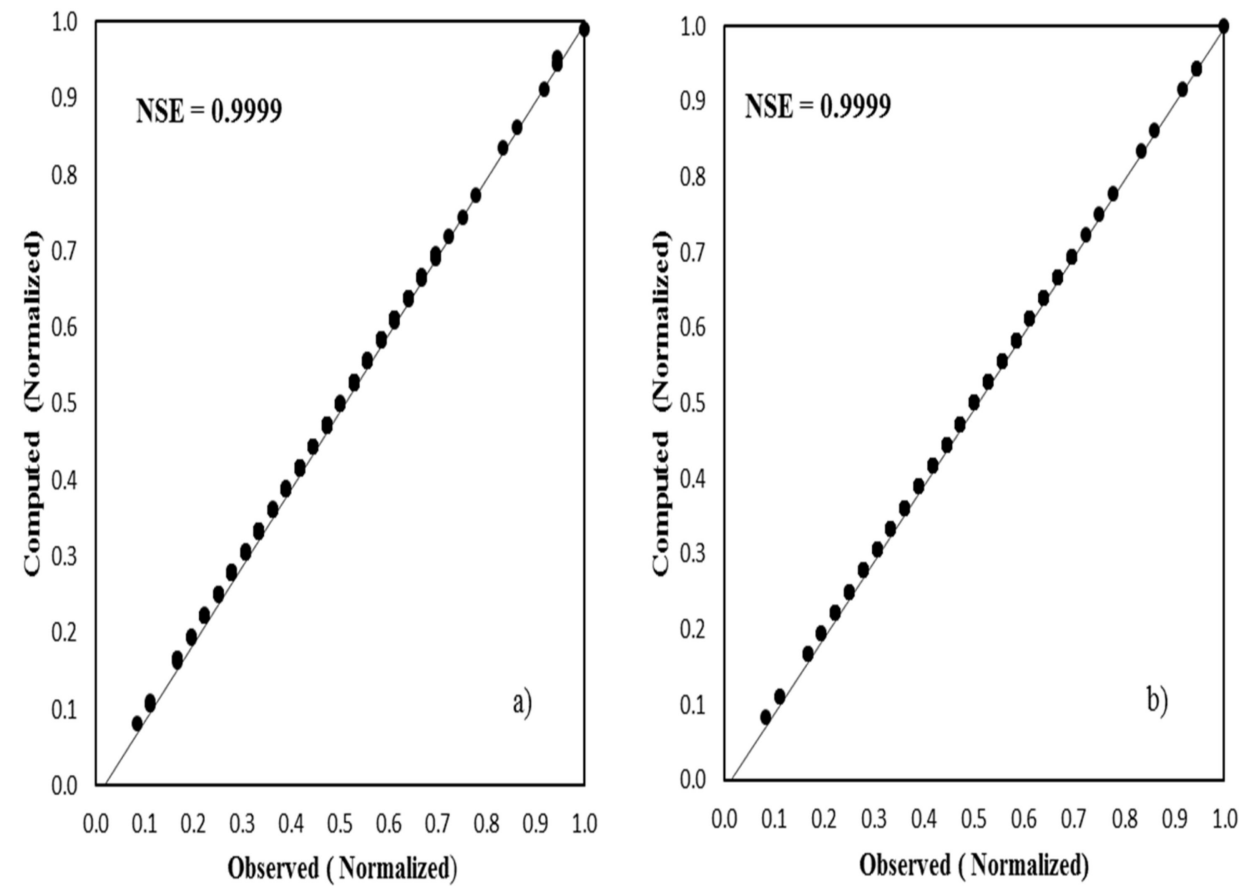

Figure 6. Scatter plots between computed and observed effects of security and privacy parameters on mobile banking apps usage by (a) Training and (b) Testing with the studied ANN model.

The training and testing values for the study ANN model was further examined using scatter plots in order to confirm the accuracy of the values obtained from the modelling results. The scatter plots computed and observed that the data produced same NSE values as that of the modelling result. The results indicate that the observed and simulated data points fitted well in the line plots, and further affirmed the model precision in making prediction. Prediction result for the developed AI-based model is presented in Figure 7.

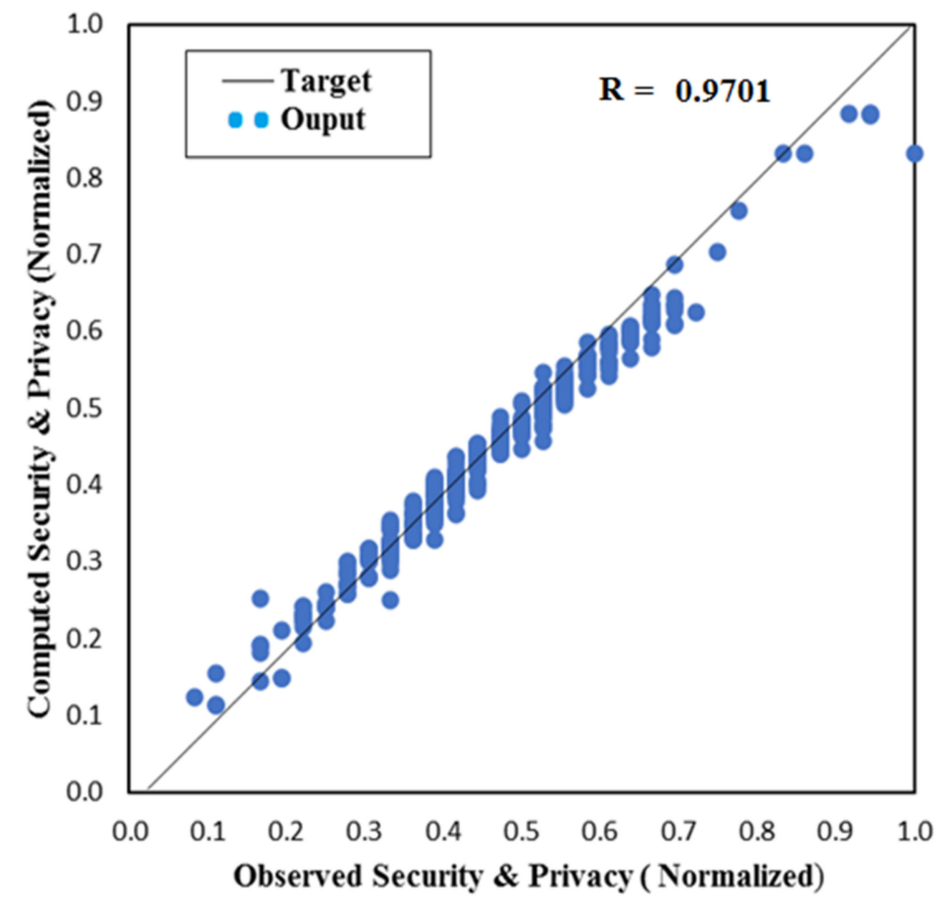

Figure 7. Predicted results of the studied ANN reported model. 
As showed in Figure 7, the reported model prediction values of (0.9701) are very close to the study target output of (1.0), this clearly showed that "Trust", "Risk", "Legal Framework", "Information and Systems qualities", and "Facilitating Conditions" were the major hindrances of mobile banking apps development in Nigeria. Furthermore, the model predicted values of 0.9701 indicated that there is a strong correlation between the study independent variables and dependent variable. The training and testing performance results, and the predicted values of the study separate parameters are presented in Table 6 .

Table 6. ANN single modelling results.

\begin{tabular}{cccccccc}
\hline Inputs & Parameters & Model & Target & Training & Testing & Prediction \\
\hline $\mathrm{H} 1 \mathrm{a}$ & Information quality $\rightarrow$ Intention to use & 1 & 1.0 & 0.9362 & 0.9280 & 0.9334 & Supported \\
$\mathrm{H} 1 \mathrm{~b}$ & Information quality $\rightarrow$ Satisfaction & 2 & 1.0 & 0.9476 & 0.9132 & 0.9570 & Supported \\
\hline $\mathrm{H} 2 \mathrm{a}$ & Service quality $\rightarrow$ Intention to use & 3 & 1.0 & 0.6238 & 0.6510 & 0.6881 & Not-Supported \\
$\mathrm{H} 2 \mathrm{~b}$ & Service quality $\rightarrow$ Satisfaction & 4 & 1.0 & 0.7124 & 0.6338 & 0.7812 & Not-Supported \\
\hline $\mathrm{H} 3 \mathrm{a}$ & System quality $\rightarrow$ Intention to use & 5 & 1.0 & 0.9646 & 0.9548 & 0.9614 & Supported \\
$\mathrm{H} 3 \mathrm{~b}$ & System quality $\rightarrow$ Satisfaction & 6 & 1.0 & 0.9614 & 0.9136 & 0.9780 & Supported \\
\hline $\mathrm{H} 4 \mathrm{a}$ & Trust $\rightarrow$ Intention to use & 7 & 1.0 & 0.9863 & 0.9794 & 0.9816 & Supported \\
$\mathrm{H} 4 \mathrm{~b}$ & Trust $\rightarrow$ Satisfaction & 8 & 1.0 & 0.9894 & 0.9361 & 0.9872 & Supported \\
\hline $\mathrm{H} 5 \mathrm{a}$ & Legal framework $\rightarrow$ Intention to use & 9 & 1.0 & 0.9836 & 0.9812 & 0.9653 & Supported \\
$\mathrm{H} 5 \mathrm{~b}$ & Legal framework $\rightarrow$ Satisfaction & 10 & 1.0 & 0.9681 & 0.9682 & 0.9791 & Supported \\
\hline $\mathrm{H} 6 \mathrm{a}$ & Risk $\rightarrow$ Intention to use & 11 & 1.0 & 0.9786 & 0.9710 & 0.9683 & Supported \\
$\mathrm{H} 6 \mathrm{~b}$ & Risk $\rightarrow$ Satisfaction & 12 & 1.0 & 0.9613 & 0.9286 & 0.9741 & Supported \\
\hline $\mathrm{H} 7 \mathrm{a}$ & Facilitating condition $\rightarrow$ Intention to Use & 13 & 1.0 & 0.9771 & 0.9673 & 0.9538 & Supported \\
$\mathrm{H} 7 \mathrm{~b}$ & Facilitating condition $\rightarrow$ Satisfaction & 14 & 1.0 & 0.9816 & 0.9654 & 0.9730 & Supported \\
\hline $\mathrm{H} 8 \mathrm{a}$ & Social influence $\rightarrow$ Intention to use & 15 & 1.0 & 0.6330 & 0.6884 & 0.6260 & Not-Supported \\
$\mathrm{H} 8 \mathrm{~b}$ & Social influence $\rightarrow$ Satisfaction & 16 & 1.0 & 0.6110 & 0.6379 & 0.7310 & Not-Supported \\
\hline
\end{tabular}

Note: 0.850 is the accepted prediction output for all the sole ANN models.

Having gotten the overall performance of the proposed ANN model as showed in Figure 7, the network was trained 16 more times, in order to test the study separate input parameters. As seen in Table 6, the targeted outputs for all the models were set to be (1.0), and the predicted values (outputs) obtained from the network models were all greater than (0.850), except for $\mathrm{H} 2$ and $\mathrm{H} 8$, signifying the superiority of ANN prediction models above the classical models (SEM), as the study SEM results supported all the hypotheses. While, the ANN prediction results show that only $\mathrm{H} 1, \mathrm{H} 3, \mathrm{H} 4, \mathrm{H} 5, \mathrm{H} 6$, and $\mathrm{H} 7$ were supported in Nigeria, for H8 (Social influence), it may be possible that non-inclusion of the participants Ethnicity in the survey form is responsible for the result. Similarly, the result for H2 (Service quality), may not be unrelated to the customers' lack of technical knowledge with regards to what constitute a service excellence in moveable banking conduits.

\section{Discussion}

The main findings are summarized based on the ANN results, due its superiority above the classic models, in this case SEM. For security and privacy matters, the ANN model-predicted values of 0.9701 exposed that customers fear of third parties seeing or accessing their confidential information while conducting online transactions through mobile banking apps (Risk), absence of sophisticated technologies and procedures that guarantee secured services offering (Trust), fear of device lost or theft with banking details, and vulnerability of the Internet environment were the major protection and secrecy issues of mobile banking apps. This result is in alignment with the findings of Munoz-Leiva [31], that security and privacy uncertainty were the main reasons for most customers' rejection of mobile banking apps. Furthermore, the study found the present rate of Internet crime (Internet fraud) also raised a lot of security concerns among the banking customers. 
For reasons behind Nigerians' snub of Internet and other moveable banking apps, the study discovered customers lack of "Trust", H4, on the network interface, banking agents or the institution itself, "Risk" involved in mobile banking H6. These results are in line with the results of Baabdullah [42] that faith and risk were the major factors responsible for non-usage of moveable banking apps. Another result that emerged from the study is absence of specific Internet laws, H5. The study found digital laws to have negative effects on moveable banking apps in Nigeria and other African states, which in turn affects its progress. Moreover, the study found poor Internet and telecommunication services, and how banks respond to customers when they experience problems with their mobile banking apps "Information Quality" H1 and "System Quality" H3, also impacted negatively on Nigerian customers' resolve to accept mobile banking apps. Another factor that has significant effect on customers' intent, is resource "Facilitating Condition" H7. This outcome is in contrast with the results of a previous study by Abbas [35] conducted in the same area. The authors argued that information and systems qualities have no influence on customers resolve to use moveable banking apps.

For the two ANN results that are not supported (H2 and H8), absence of participants' Ethnicity in social influence dimension in the survey form may likely be responsible for H8 result, while $\mathrm{H} 2$ result, may not be unconnected with customers inability to understand what constitute service excellence due to lack of technical knowledge with regards to mobile banking services. Similarly, the two results of (H2 and H8), signify the superiority of ANN prediction model, as it exposed the absence of Ethnicity dimension in the survey constructs and customers' lack of technical knowhow with regards to service quality.

\section{Conclusions, Recommendations, and Future Work}

In this study, effects of safety and confidentiality issues on customers' intent to accept and use mobile banking apps in developing nations, especially Nigeria were investigated and modelled using AI-based approach (ANN). The prediction results show that security and privacy matters impacted negatively on customers' intent to use mobile banking conduits in Nigeria. Furthermore, the results of the AI-based approach tests showed that the proposed research model can be accepted and used to determine the factors that affect customers' intention to use mobile banking apps in Nigeria and of course other developing countries. Furthermore, the research exposed the issues responsible for Nigerians' refusal to embrace or continual usage of mobile banking apps. The study results also proved the superiority of ANN prediction model above the usual empirical models, in this case (SEM). The study hypotheses were tested twice using SEM and ANN. The main focus of this study was to use ANN prediction model in order to determine the effects of safety and confidentiality parameters on the intent to use and continual usage of mobile banking apps in Nigeria. Findings of the study delivered support the proposed research model, as it provides evidence that "Risk", "Trust", and "Legal Framework" were the main reasons for Nigerians' refusal to accept mobile banking apps. It may be possible that the mode of distributing the study questionnaire helped in achieving these results, as the participants were spread across all parts of the country. Other factors that emerged from the study results were "Information and Systems Quality" issues. The study results showed that, the quality of information and systems provided by pecuniary institutes with regards to mobile banking apps in Nigeria was poor, thus affecting customers' intention to use the new service platforms negatively. Furthermore, situations of resources that enable mobile banking usage contributed to people refusal. Banks and financial organizations can use the study outcomes to deploy more sophisticated technologies that can guarantee secured services and develop customers enlightenments strategies in order to improve the adoption level. Similarly, government authorities can use the findings to come up with specific legislation that would safeguard customers' interests in the cyberspace. From academic point of view, the study findings contribute to the existing $\mathrm{m}$-banking literatures, proved the superiority of AI-based models such as ANN, ANFIS, and CNN models above empirical 
models e.g., SEM. Moreover, it will serve as a motivation for scholars to embrace AI-based techniques due its accuracy, flexibility, and robustness.

The limitations of this study are that the selected participants comprise only customers, without considering other stakeholders such as banks officials, telecommunication and Internet services providers, and government regulatory bodies. Second, this paper only investigates the issues that led to the low-level usage of mobile banking apps in relation to security and privacy issues with special consideration to "Legal Framework, Trust and Risk". Therefore, upcoming studies should investigate other factors from ethical and morals principles as Nigeria has over 371 ethnic groups with a diverse cultural background. Furthermore, future works should involve other stakeholders in the sector. Nowadays, computers applications are increasingly becoming part of peoples' lives, and peoples attitudes toward these applications affect the interaction. This affiliation differs between individuals and regions across the globe. Thus, the study concepts can be applied in other nations, to gain more insights into innovative safety and secrecy hitches.

Author Contributions: Methodology: N.C., Y.B.M., M.N.Y.; conceptualization: N.C., Y.B.M. and M.N.Y.; investigation: N.C., Y.B.M. and M.N.Y.; data curation: M.N.Y., Y.B.M. and N.C.; writing: N.C., Y.B.M., M.N.Y.; writing-review and editing: N.C. and Y.B.M. All authors have read and agreed to the published version of the manuscript.

Funding: The study is funded by the authors.

Institutional Review Board Statement: The study was conducted according to the guidelines of the Declaration of Helsinki, and it was approved by the Scientific Research Ethics Committee of Near East University with approval number (YDÜ/FB/2020/90) dated 27 April 2020.

Informed Consent Statement: Informed consent was obtained from all the participants involved in this study.

Data Availability Statement: The study data is available on request at Near East University, NicosiaCyprus, Department of Computer Information Systems.

Acknowledgments: The authors wish to extend our appreciation to Sujeet Kumar Sharma of MIS Area, Indian Institute of Management, Tiruchirappalli, India for their contribution towards the success of this work.

Conflicts of Interest: As for this study, no conflict of interest is declared.

\section{Appendix A}

Table A1. Study input parameters, and source.

\begin{tabular}{|c|c|c|}
\hline Inputs Parameters & Items (Strongly Disagree-Strongly-Agree, 1-5 Scale) & Source \\
\hline \multirow[t]{3}{*}{ Information quality } & "The information provided by mobile banking is up-to-date" & {$[25,29]$} \\
\hline & "The information provided by m-banking is easy to understand" & \\
\hline & "The information provided by m-banking is complete" & \\
\hline \multirow[t]{3}{*}{ Service quality } & $\begin{array}{l}\text { "The call center representatives always help me when I need support with } \\
\text { m-banking" }\end{array}$ & {$[25,29]$} \\
\hline & $\begin{array}{c}\text { "The call center representatives always pay personal attention when I experience } \\
\text { problems with m-banking" }\end{array}$ & \\
\hline & $\begin{array}{c}\text { "The call center representatives have adequate knowledge to answer my queries } \\
\text { related to m-banking" }\end{array}$ & \\
\hline \multirow[t]{3}{*}{ System quality } & "The mobile banking app is easy to navigate". & {$[25,29]$} \\
\hline & "The mobile banking app is well structured" & \\
\hline & "The mobile banking is easy to use" & \\
\hline
\end{tabular}


Table A1. Cont.

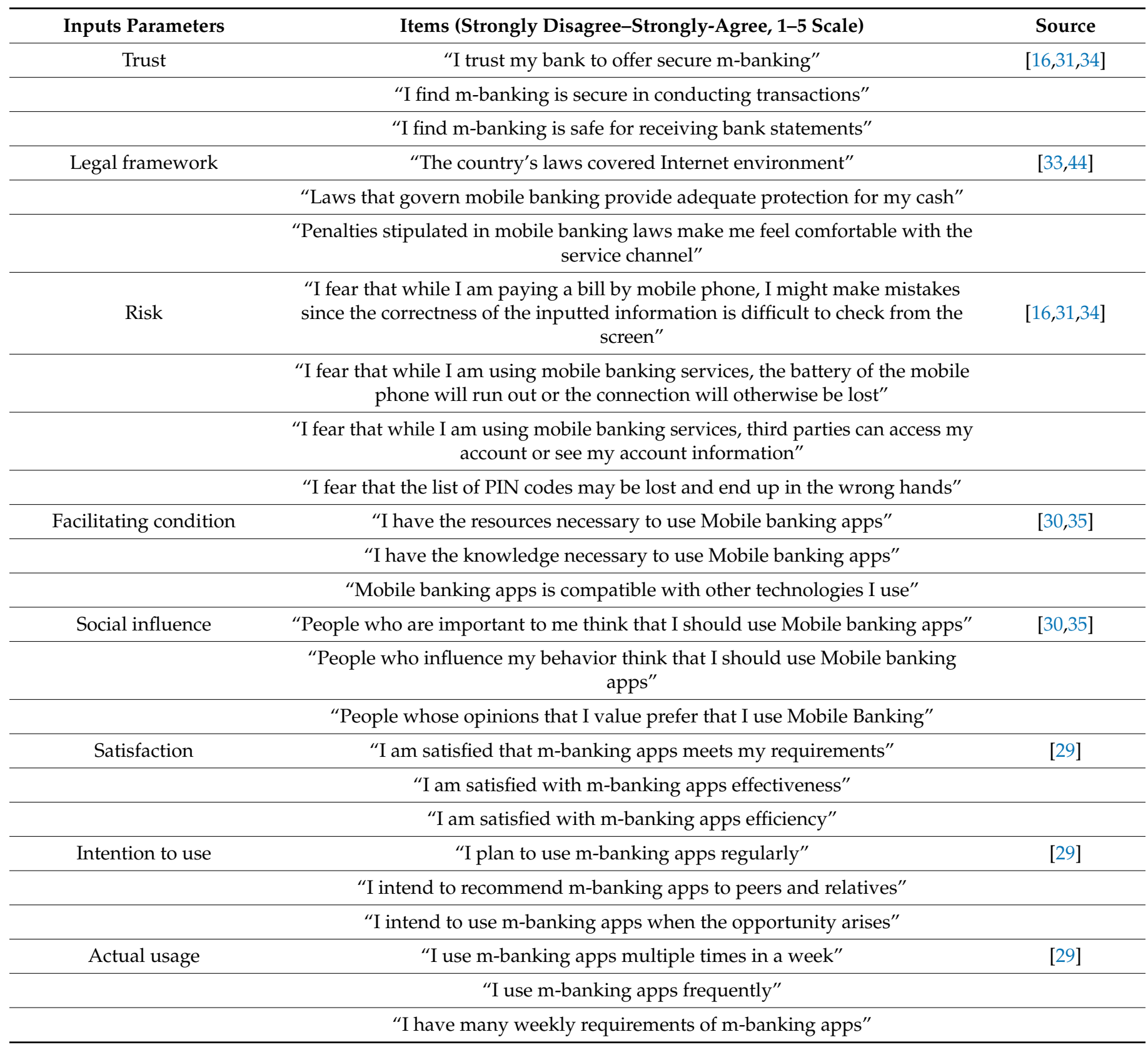

\section{References}

1. Malaquias, R.F.; Hwang, Y. Mobile banking use: A comparative study with Brazilian and US participants. Int. J. Inf. Manag. 2019, 44, 132-140. [CrossRef]

2. Yigitcanlar, T.; Cugurullo, F. The sustainability of artificial intelligence: An urbanistic viewpoint from the lens of smart and sustainable cities. Sustainability 2020, 12, 8548. [CrossRef]

3. Zhang, X. Exploring the patterns and determinants of the global mobile divide. Telemat. Inform. 2017, 34, 438-449. [CrossRef]

4. Bagudu, H.D.; Khan, M.; Jan, S.; Roslan, A.-H. The Effect of Mobile Banking on the Performance of Commercial Banks in Nigeria. Int. Res. J. Manag. IT Soc. Sci. 2017, 4, 71-76. Available online: https://creativecommons.org/licenses/by-sa/4.0/ (accessed on 31 March 2021).

5. Schuetz, S.; Venkatesh, V. Blockchain, adoption, and financial inclusion in India: Research opportunities. Int. J. Inf. Manag. 2019, 101936. [CrossRef]

6. Raza, S.A.; Umer, A.; Shah, N. New determinants of ease of use and perceived usefulness for mobile banking adoption. Int. J. Electron. Cust. Relatsh. Manag. 2017, 11, 44-65. [CrossRef] 
7. Dandena, S.; Abera, T.M.; Mengesha, T. Factors affecting the adoption of mobile banking: The case of United Bank Addis Ababa city customers. J. Process. Manag. New Technol. 2020, 8, 30-37. Available online: http://scindeks.ceon.rs/article.aspx?artid=2334-7 35X2001030D (accessed on 31 March 2021). [CrossRef]

8. Verkijika, S.F. Factors influencing the adoption of mobile commerce applications in Cameroon. Telemat. Inform. 2018, 35, 1665-1674. [CrossRef]

9. Malaquias, R.F.; Hwang, Y. An empirical study on trust in mobile banking: A developing country perspective. Comput. Hum. Behav. 2016, 54, 453-461. [CrossRef]

10. Baptista, G.; Oliveira, T. A weight and a meta-analysis on mobile banking acceptance research. Comput. Hum. Behav. 2016, 63, 480-489. [CrossRef]

11. Merhi, M.; Hone, K.; Tarhini, A. A cross-cultural study of the intention to use mobile banking between Lebanese and British consumers: Extending UTAUT2 with security, privacy and trust. Technol. Soc. 2019, 59, 101151. [CrossRef]

12. Abayomi, O.J.; Olabode, A.C.; Reyad, M.A.H.; Teye, E.T.; Haq, M.N.; Mensah, E.T. Effects of Demographic Factors on Customers' Mobile Banking Services Adoption in Nigeria. Int. J. Bus. Soc. Sci. 2019, 10, 63-77. [CrossRef]

13. Osho, O.; Mohammed, U.L.; Nimzing, N.N.; Uduimoh, A.A.; Misra, S. Forensic Analysis of Mobile Banking Apps. In Proceedings of the International Conference on Computational Science and Its Applications, Saint Petersburg, Russia, 1-4 July 2019; pp. 613-626. [CrossRef]

14. Satrya, G.B.; Shin, S.Y. Proposed method for mobile forensics investigation analysis of remnant data on Google Drive client. J. Internet Technol. 2018, 19, 1741-1751. Available online: https:/ /jit.ndhu.edu.tw/article/view/1795 (accessed on 31 March 2021).

15. Cavus, N.; Christina, D.N.C. Information technology in the banking sector: Review of mobile banking. Glob. J. Inf. Technol. Emerg. Technol. 2015, 5, 62-70. [CrossRef]

16. Sharma, S.K.; Sharma, M. Examining the role of trust and quality dimensions in the actual usage of mobile banking services: An empirical investigation. Int. J. Inf. Manag. 2019, 44, 65-75. [CrossRef]

17. Tijani, J.; Ilugbemi, A. Electronic payment channels in the Nigeria banking sector and its impacts on national development. Asian Econ. Financ. Rev. 2015, 5, 521-531. [CrossRef]

18. Shaikh, A.A.; Karjaluoto, H. Mobile banking adoption: A literature review. Telemat. Inform. 2015, 32, 129-142. [CrossRef]

19. Hassan, H.E.; Wood, V.R. Does country culture influence consumers' perceptions toward mobile banking? A comparison between Egypt and the United States. Telemat. Inform. 2020, 46, 101312. [CrossRef]

20. Eshet, E.; Bouwman, H. Addressing the Context of Use in Mobile Computing: A Survey on the State of the Practice. Interact. Comput. 2015, 27, 392-412. [CrossRef]

21. Lange, R.; Burger, E.W. Long-term market implications of data breaches, not. J. Inf. Priv. Secur. 2017, 13, 186-206. [CrossRef]

22. Kim, Y.; Wang, Q.; Roh, T. Do information and service quality affect perceived privacy protection, satisfaction, and loyalty? Evidence from a Chinese O2O-based mobile shopping application. Telemat. Inform. 2020, 101483. [CrossRef]

23. Rahi, S.; Ghani, M.A. A structural equation modeling (SEM-AMOS) for investigating brand loyalty and customer's intention towards adoption of internet banking. In Proceedings of the 29th International Scientific Conference on Economic and Social Development, Rabat, Morocco, 10-11 May, 2018; pp. 206-220. Available online: https://www.esd-conference.com/conference/30 (accessed on 18 December 2018).

24. Shaikh, A.A.; Glavee-Geo, R.; Karjaluoto, H. How relevant are risk perceptions, effort, and performance expectancy in mobile banking adoption? Int. J. E-Bus. Res. 2018, 14, 39-60. [CrossRef]

25. Urbach, N.; Ahlemann, F. Structural equation modeling in information systems research using partial least squares. J. Inf. Technol. Theory Appl. 2010, 11, 5-40. Available online: https://aisel.aisnet.org/jitta/vol11/iss2/2 (accessed on 31 March 2021).

26. Nourani, V.; Gökçekuş, H.; Umar, I.K. Artificial intelligence based ensemble model for prediction of vehicular traffic noise. Environ. Res. 2020, 180, 108852. [CrossRef]

27. Cavus, N.; Mohammed, Y.B.; Yakubu, M.N. Determinants of Learning Management Systems during COVID-19 Pandemic for Sustainable Education. Sustainability 2021, 13, 5189. [CrossRef]

28. DeLone, W.H.; McLean, E.R. Information systems success revisited. In Proceedings of the 35th Annual Hawaii International Conference on System Sciences, Big Island, HI, USA, 10 January 2002; pp. 2966-2976. [CrossRef]

29. Tam, C.; Oliveira, T. Understanding the impact of $m$-banking on individual performance: DeLone \& McLean and TTF perspective. Comput. Hum. Behav. 2016, 61, 233-244. [CrossRef]

30. Venkatesh, V.; Thong, J.Y.; Xu, X. Consumer acceptance and use of information technology: Extending the unified theory of acceptance and use of technology. MIS Q. 2012, 157-178. [CrossRef]

31. Munoz-Leiva, F.; Climent-Climent, S.; Liébana-Cabanillas, F. Determinants of intention to use the mobile banking apps: An extension of the classic TAM model. Span. J. Mark. ESIC 2017, 21, 25-38. [CrossRef]

32. Ntseme, O.J.; Nametsagang, A.; Chukwuere, J.E. Risks and benefits from using mobile banking in an emerging country. Risk Gov. Control Financ. Mark. Inst. 2016, 6, 355-363. [CrossRef]

33. Weber, R.H.; Darbellay, A. Legal issues in mobile banking. J. Bank. Regul. 2010, 11, 129-145. [CrossRef]

34. Luo, X.; Li, H.; Zhang, J.; Shim, J.P. Examining multi-dimensional trust and multi-faceted risk in initial acceptance of emerging technologies: An empirical study of mobile banking services. Decis. Support Syst. 2010, 49, 222-234. [CrossRef]

35. Abbas, S.K.; Hassan, H.A.; Asif, J.; Ahmed, B.; Haider, S.S. Integration of TTF, UTAUT, and ITM for mobile Banking Adoption. Int. J. Adv. Eng. Manag. Sci. 2018, 4. [CrossRef] 
36. Calisir, N.; Basak, E.; Calisir, F. Key drivers of passenger loyalty: A case of Frankfurt-Istanbul flights. J. Air Transp. Manag. 2016, 53, 211-217. [CrossRef]

37. Zhou, Y.; Wang, H.; Xu, F.; Jin, Y.-Q. Polarimetric SAR image classification using deep convolutional neural networks. IEEE Geosci. Remote Sens. Lett. 2016, 13, 1935-1939. [CrossRef]

38. Lee, H.S.; Lee, J. Applying Artificial Intelligence in Physical Education and Future Perspectives. Sustainability 2021, $13,351$. [CrossRef]

39. Van Gerven, M.; Bohte, S. Artificial neural networks as models of neural information processing. Front. Comput. Neurosci. 2017, 11, 114. [CrossRef] [PubMed]

40. Mohammed, Y.B.; Karagozlu, D. A Review of Human-Computer Interaction Design Approaches towards Information Systems Development. Brain. Broad Res. Artif. Intell. Neurosci. 2021, 12, 229-250. [CrossRef]

41. Rahman, A.; Hasan, M.; Mia, M.A. Mobile banking service quality and customer satisfaction in Bangladesh: An analysis. Cost Manag. 2017, 45, 25-32.

42. Baabdullah, A.M.; Alalwan, A.A.; Rana, N.P.; Kizgin, H.; Patil, P. Consumer use of mobile banking (M-Banking) in Saudi Arabia: Towards an integrated model. Int. J. Inf. Manag. 2019, 44, 38-52. [CrossRef]

43. Gupta, S.; Yun, H.; Xu, H.; Kim, H.-W. An exploratory study on mobile banking adoption in Indian metropolitan and urban areas: A scenario-based experiment. Inf. Technol. Dev. 2017, 23, 127-152. [CrossRef]

44. Han, C.; Yang, S. Value-based adoption of mobile banking service: A multi-channel perspective. In Proceedings of the 2010 International Conference on Information, Networking and Automation (ICINA), Kunming, China, 18-19 October 2010; pp. V2-506-V2-510. [CrossRef]

45. Rasull, A.; Jantan, A.H.; Ali, M.H.; Jaharudin, N.S.; Mansor, Z.D. Benefit and Sacrifice Factors Determining Internet Banking Adoption in Iraqi Kurdistan Region. J. Int. Bus. Manag. 2020, 3, 1-20. [CrossRef]

46. Sharma, S.K. Integrating cognitive antecedents into TAM to explain mobile banking behavioral intention: A SEM-neural network modeling. Inf. Syst. Front. 2019, 21, 815-827. [CrossRef]

47. Tarute, A.; Nikou, S.; Gatautis, R. Mobile application driven consumer engagement. Telemat. Inform. 2017, 34, 145-156. [CrossRef]

48. Amankwah-Amoah, J.; Osabutey, E.L.; Egbetokun, A. Contemporary challenges and opportunities of doing business in Africa: The emerging roles and effects of technologies. Technol. Forecast. Soc. Chang. 2018, 131, 171-174. [CrossRef]

49. Uduimoh, A.A.; Osho, O.; Ismaila, I.; Shafi'i, M.A. Forensic Analysis of Mobile Banking Applications in Nigeria. i-Manag. J. Mob. Appl. Technol. 2019, 6, 9-20. [CrossRef]

50. Inegbedion, H.E. Factors that influence customers' attitude toward electronic banking in Nigeria. J. Internet Commer. 2018, 17, 325-338. [CrossRef]

51. Hanafizadeh, P.; Behboudi, M.; Koshksaray, A.A.; Tabar, M.J.S. Mobile-banking adoption by Iranian bank clients. Telemat. Inform. 2014, 31, 62-78. [CrossRef]

52. Chyung, S.Y.; Roberts, K.; Swanson, I.; Hankinson, A. Evidence-based survey design: The use of a midpoint on the Likert scale. Perform. Improv. 2017, 56, 15-23. [CrossRef]

53. Zhou, T.; Lu, Y.; Wang, B. Integrating TTF and UTAUT to explain mobile banking user adoption. Comput. Hum. Behav. 2010, 26, 760-767. [CrossRef]

54. Haider, M.J.; Changchun, G.; Akram, T.; Hussain, S.T. Exploring gender effects in intention to islamic mobile banking adoption: An empirical study. Arab Econ. Bus. J. 2018, 13, 25-38. [CrossRef]

55. Taber, K.S. The use of Cronbach's alpha when developing and reporting research instruments in science education. Res. Sci. Educ. 2018, 48, 1273-1296. [CrossRef]

56. Li, X.; Ding, Q.; Sun, J.-Q. Remaining useful life estimation in prognostics using deep convolution neural networks. Reliab. Eng. Syst. Saf. 2018, 172, 1-11. [CrossRef]

57. Li, G.; Shi, J. On comparing three artificial neural networks for wind speed forecasting. Appl. Energy 2010, 87, 2313-2320. [CrossRef]

58. Reim, W.; Åström, J.; Eriksson, O. Implementation of Artificial Intelligence (AI): A Roadmap for Business Model Innovation. AI 2020, 1, 180-191. [CrossRef] 